Www.jmscr.igmpublication.org

Impact Factor (SJIF): 6.379

Index Copernicus Value: 79.54

ISSN (e)-2347-176x ISSN (p) 2455-0450

crossrefDOI: https://dx.doi.org/10.18535/jmscr/v6i10.141

Journal Of Medical Science And Clinical Research

IGM Publication

An Official Publication of IGM Publication

\title{
Instant Swaddle Use to Improve the Body's Temperature of Newborn Baby
}

\author{
Authors \\ Nora Isa Tri Novadela ${ }^{1}$, Sudarmi ${ }^{2}$ \\ ${ }^{1,2}$ Department of Midwifery Poltekkes Ministry of Health of Tanjung Karang \\ Corresponding Author \\ Nora Isa Tri Novadela \\ Email: Noraisatrinovadela@yahoo.co.id
}

\begin{abstract}
Background: This research aims to find out the comparison of the instant and conventional swaddle to the body temperature of a newborn baby in South Lampung Regency.

Methods: Samples in this study amounted to 50 newborn babies who were grouped into 2: intervention groups totaling 25 newborn babies and a control group of 25 newborn babies. This study used a quantitative design, type of true-experiment with pre and post-test design and double-blinded method to compare the intervention group and the control group.

Results: Statistical test results obtained p-value $=0.37$, meaning that there is a significant difference between the baby's body temperature using instant and conventional swaddle. Baby's body temperature using instant swaddle is more comfortable than babies who use conventional swaddle. A baby who use swaddle instantly sleep more soundly and longer than babies who use conventional swaddle. Midwives are faster and more efficient in using instant swaddle compared to wearing conventionalswaddle.

Conclusions: Socialization and application of the use of instant swaddle, especially in newborn babies are compulsory. Instant swaddle is also very useful when used in healthcare units that do not have an incubator, because it increases body temperature of newborn babies, in addition to thelow price, easy to make and very safe and comfortable for babies.

Keywords: Instant swaddle, Conventionalswaddle, Body temperature, Newborn baby.
\end{abstract}

\section{Introduction}

Average body temperature in newborns ranges from 36.5 - $37.5^{\circ} \mathrm{C}$. Body temperature of a newborn baby must be maintained to remain normal, if not managed, the baby's condition can fall in hypothermic conditions. In a newborn baby that experience hypothermia, metabolism will increase, oxygen demand will improve, resulting in apnea, heart failure, pulmonary hemorrhage, jaundice and ultimately can interfere with baby's growth and development, even causes death (Kelmanson, 2006).
Maintaining body temperature ofnewborn babies is essential. A mother or midwife can make several efforts to warm and sustain a baby's body temperature. The first effort that can be done is breastfeeding, the second attempt can be created with the kangaroo method, and the next effort is to baby sowing and placing in a warm room. Some medical studies have found the benefits of baby's swaddles, namely, reducing the risk of SIDS (Sudden Infant Death Syndrome), calming the baby, exercising his movements, overcoming the 
baby's crying and making the baby sleep better (Kuhu,1990).

It has become a habit that every newborn baby is dissected up to several months old. Swaddle is believed to help straighten the baby's legs when born tend to be bent like a frog's leg. Besides, babies are calmer because the baby feels warmer and more comfortable like when he wasin the womb. For that, the baby is more comfortable to carry and easy to carrybreastfeeding because hands and feet did not move erratically (Van,2007).

According to Hidayat (2007), a baby coat is baby care that almost all countries use before the 18th century. It is still a tradition in some parts of the Middle East, England, United States, and the Netherlands to reduce excessive crying and comfort for babies. In Indonesia, the use of swaddle is widespread and has been carried out for generations.

However, in reality, the use of conventional swaddle by some mothers is still wrong, where the swaddle is forced to force the baby's legs to be straight. According to Lipton (1965), "surgery aims to warm the baby and not to straighten the baby's legs. The normal position of the baby's legs is somewhat crooked, so parents don't need to worry.

Considering the critical role of swaddle in maintaining body temperature, researchers are trying to develop swaddle models which are expected to be warmer, practical, effective and efficient. The swaddle researchers call Instant Swaddle, which stands for the warm and instant swaddle, where researchers attempt to modify the conventional swaddle into a solid drum with a zipper on the front, and there is a pocket on the left and right of the baby's chest. In the pocket, the section can be filled with balloons that contain warm water so that the swaddles not only maintains body temperature newborn babies but also can increase body temperature of newborn babies.

The use of swaddle in Indonesia is pervasive, even to Lampung and all corners of the district. South
Lampung Regency consists of 17 sub-districts, in which 56 independent midwives practitioners spread all regions. Of these, all practitioners still use conventional swaddle. Therefore researchers are interested in examining the body temperature comparison of newborn babies that use instant and modern swaddle.

\section{Methods}

This study uses a quantitative design, type of trueexperiment with designs pre and post-test and methods double-blinded to compare the intervention group and the control group. It is considered the classified research of trueexperimental because in the sampling and determination of the intervention group and the control group apply a system of simple random sampling. Classified as pre and post-test design as data collection was done before and after the intervention.

\section{Results}

Based on the univariate analysis, the average body temperature of a newborn baby before using instant swaddle is $36.3^{\circ} \mathrm{C}$ (mild hypothermia), after using instant swaddle for twelve hours, an increase in the average body temperature newborn babyis $36.8^{\circ} \mathrm{C}$ (normal). The average body temperature of a newborn baby before using conventional swaddles is $36.2^{\circ} \mathrm{C}$ (mild hypothermia), after using conventional swaddle for twelve hours, an increase in the average body temperature of new babies bornis $36.5^{\circ} \mathrm{C}$ (average).

Based on univariate analysis it is known that the average length of time a baby sleeps when using instant swaddle is for 9 hours 24 minutes, while the average range of a baby rests when using conventionalswaddle is for 6 hours 28 minutes.

Based on bivariate analysis results in the average baby's body temperature after using instant swaddle was $36.79^{\circ} \mathrm{C}$ with a standard deviation of 0.22 , while the average body temperature of the baby after using conventionalswaddle was $36.54^{\circ} \mathrm{C}$ with a standard deviation of 0.54 . 
Statistical test results obtained p-value $=0.37$, meaning that there is a significant difference between the baby's body temperature using instant swaddle and conventionalswaddle. The average length of sleep for babies who use instant swaddle is 9 hours 24 minutes with a standard deviation of 0.78 while the average range of rest for babies who use conventional beds is 6 hours 28 minutes with a standard deviation of 1.1. Statistical test results obtained $\mathrm{p}$-value $=0,000$ indicating that there is a significant difference between the length of baby sleep using instant swaddle and using conventionalswaddle.

\section{Discussion}

According to Prawiroharjo(2001), the effect of baby swaddles can foster a relaxed attitude towards the baby disruption of things, create warmth, soothe the baby, and help physical perfection. The swaddles will help the baby's bones remain straight and avoid bone defects due to the high weight of babies. After the study, it was found that the average body temperature of the baby before using instant swaddle was $36.3^{\circ}$ $\mathrm{C}$ (having mild hypothermia), while the average body temperature of the baby after using instant swaddle for twelve hours increased to normal $\left(36.8^{\circ} \mathrm{C}\right)$. From the results of statistical tests, it is known that there is a significant difference between the baby's body temperature before and after using instant swaddle. Similarly, the use of conventional swaddle, the average body temperature of the baby before using conventional swaddle is $36.22^{\circ} \mathrm{C}$ (experiencing mild hypothermia), whereas the average body temperature of the baby after using conventional swaddle increases to normal $\left(36.54^{\circ} \mathrm{C}\right)$. Statistical test results revealed that there were significant differences between the baby's body temperature before and after using conventional swaddle.

The average baby's body temperature after using instant swaddle was $36.79^{\circ} \mathrm{C}$, while the average body temperature of the baby after using conventional swaddle was $36.54^{\circ} \mathrm{C}$. The results of statistical tests revealed that there were significant differences between the increase in the baby's body temperature using Instant swaddle and conventional swaddle. Although both body temperature increases occur at newborn babies after twelve hours using both different types of the swaddle, apparently the use of instant swaddle is more useful to improve and maintain normal body temperature in newborn babies.

According to Blom (2005), In general, newborns experience mild hypothermia, and it is possible because of many factors, including due to the newborn baby still adapts from the condition in the uterus to a state outside the womb. The center of the body temperature regulation in infants has not functioned correctly that the baby's body is too small to produce and to store heat, and the baby has also not been able to adjust body position and clothes so as not to get cold. Even so, babies can also produce body heat by metabolizing brown fat reserves throughout the body. To burn brown fat, babies must use glucose to get the energy that will convert fat into body heat. Newborn babies can not reproduce brown fat, and brown fat reserves will run out in a short time in cold stress conditions. If the supply of brown fat is exhausted, the metabolic response to cold will decrease. Therefore, it is essential for midwives to prevent hypothermia in newborn babies, one of which is the correct and effective use of swaddle (Campos, 1989).

According to the analysis of the researchers, the increase in body temperature of newborn babies after using instant swaddle was more significant than using conventionalswaddle, made possible by the use of warm balloons in the four pockets at instant swaddle, on both the left and right chest and left and right abdomen. The warm temperature of the device $\left(38^{\circ} \mathrm{C}\right)$ will be transferred to the baby's body through the conduction process, so instant swaddle does not only function to maintain a body temperature of newborn babies but also works to increase body temperature, newborn babies. Researchers hope instant swaddle can be used not only by the wider community, but also health facilities mainly in 
health community centers or hospitals in remote areas that do not have an incubator.

Babies who use instant swaddle sleep much more prolonged than babies who use conventional swaddle, this is because, in the instant swaddle, the baby's motion in the swaddle is relatively more comprehensive, so that the position of the baby's feet can resemble the area of feet while in the womb (bent at the knee). At the conventional beds, the location of the baby's legs is straightened, so the baby is forced to be as soon as possible to adapt to the situation in the swaddle. Thus, the baby's body position is more comfortable using instant swaddle compared to conventionalswaddle (Bolton,1996).

Given the importance of adequate sleep in infants, researchers suggest midwives use instant swaddle as an effort meeting the needs of comfort in newborn babies. In comfortable conditions, babies can sleep more soundly and longer, so instant swaddle can increase intelligence and increase the weight of a newborn baby. The average length of a baby rests when using instant swaddle is for 9 hours 24 minutes, while the average range of a baby sleeps when using conventional swaddles is for 6 hours 28 minutes. From the results of statistical tests, it is known that there is a significant difference between the length of baby sleep when using instant swaddle and when using conventional swaddle.

Sleep plays an essential role in the process of child development. Rest plays a role in precipitating various experiences while awake and discarding unwanted experiences. In sleep, many brain cell activations play a significant role in the development of brain maturity in the first years of life. Sleep also has therapeutic properties related to maintaining endurance and physical development, eliminating fatigue, and improving focus and concentration. (Chisholm, 1978).

The speed of the midwife in applying instant swaddle at newborn babies is 19.57 seconds, while the rate of the midwife in wearing conventional swaddle at newborn babies is $\mathbf{5 2 . 7 6}$ seconds. The use of swaddle is relatively effective and efficient because it only requires a short, comfortable and practical time.

\section{Conclusion}

The body temperature of newborn babies before using swaddle instant is $36.356^{\circ} \mathrm{C}$, after using instant swaddle is $36.796^{\circ} \mathrm{C}$. Body temperature newborn baby before using conventional swaddle is $36.224^{\circ} \mathrm{C}$, after using conventional swaddle $36.720^{\circ} \mathrm{C}$. Length of baby sleeping while using instant swaddle is 9 hours 24 minutes, while newborn baby using conventional swaddle is 6 hours 28 minutes. The body temperature of babies using instant swaddle has more improvement than babies who use conventional swaddle. Midwives are faster and more efficient in using instant swaddle compared to wearing conventional swaddles. Babies who are using instant swaddle sleep is more sound and longer than babies who use conventional bedbugs.

\section{References}

1. Blom MA. (2005). Menangis dan Gelisah pada Bayi: Panduan Orang Tua Untuk Tidur Alami. Edinburg, Scotlandia

2. Bolton DP, Nelson EA, Taylor BJ, Weatherall IL. (1996). Keseimbangan Termal Pada Bayi. J Appl Physiol. 1996; 80: 2234-2242

3. Campos RG. (1989). Soothing painelicited distress in infants with swaddling and pacifiers. Child Dev.1989;60:781-792

4. Chisholm JS.(1978). Swaddling, cradleboards dan perkembangan AnakAnak. Awal Hum Dev. 1978; 2 ; 255-291

5. Hidayat, A.A., (2007). Metode Penelitian Kebidanan Teknik Analisis Data. Jakarta: Salemba Medika

6. Kelmanson IA, Adults El. (2006). Massage therapy and sleep behavior in infants born with low birth weight. Complement Thor Clip Pract

7. Kutlu A, Memik R, Mutlu M, Arslan A. (1990). Congenital dislocation of the hip 
and its relation to swaddling used in Turkey. J Public Health

8. Lipton EL, Steinschneider A., Richmond JB. (1965). Swaddling, Praktik Perawatan Anak Observasi Historic, Budaya dan Experimental. Pediatric. 1965; 35 (suppl): 521-567

9. Prawirahardjo, Sarwono. (2001) . Ilmu Kebidanan. Jakarta: YBPSP

10. Van Sleuwen, Bregje. (2007) . Swaddling: Sebuah tinjauan Sistematik. AAP News \& Journals Gateway Pediatrics. Vol 120 / Issue 4. 